\title{
Thermal Stimulated Conductivity in Cellulose Triacetate-Multiwalled Carbon Nanotube Polymer Films
}

\author{
C. Basavaraja, Eun Ae Jo, Bong Sung Kim, and Do Sung Huh* \\ Department of Chemistry and Institute of Basic Science, Inje University, Kimhae, Kyungnam 621-749, Korea \\ *E-mail: chemhds@inje.ac.kr \\ Received February 15, 2010, Accepted June 12, 2010
}

\begin{abstract}
This paper describes the preparation and study of thermally stimulated discharge conductivity (TSDC) study of cellulose triacetate (CTA) - multiwalled carbon nanotubes (MWNTs) film thermoelectrets. TSDC has been carried out in the temperature range $308-503 \mathrm{~K}$ and at four different polarizing fields. The conductivity of the polymer blends increased with increase in temperature showing a semi-conducting behavior. The apparent activation energy also showed a pronounced effect with the increase in the content of MWNTs.
\end{abstract}

Key Words: Cellulose triacetate, Composite film, DC conductivity, Multiwalled carbon nanotubes

\section{Introduction}

There has been increasing interest in the development of electronic circuits on flexible substrates to meet the growing demand for low-cost, large-area, flexible and lightweight devices, such as roll-up displays, e-papers, connectors, and keyboards. Organic/polymer and nanocomposite materials have attracted a lot of attention for building large-area, mechanically flexible electronic devices. ${ }^{1,2}$ These materials are widely pursued since they offer numerous advantages in terms of ease of processing, good compatibility with a variety of substrates, and great opportunity for structural modifications. Organic lightemitting diodes for flat-panel displays appear ready for mass production, ${ }^{3,4}$ and significant progress has also been made in organic thin-film transistors ${ }^{5}$ and solar cells. ${ }^{6,7}$ There is also a strong desire to develop new, large-scale advanced materials that can meet the growing demand for miniaturization, highspeed performance, and flexibility for microelectronic products.

In this regard, natural fibers have emerged as renewable and biodegradable natural materials. They are becoming increasingly useful as raw materials for the preparation of cost-effective and environment-friendly composite materials. In fact, despite their relatively modest strength and low density, plant fibers have been found to be capable of producing fibrous composites with high-specific strength. ${ }^{8-17}$ Cellulose acetate and cellulose triacetate (CTA) are extensively used in the preparation of hemodialysis and desalination membranes. ${ }^{10}$ Acetate and triacetate fibers of cellulose have lower strength and abrasion resistance than most man-made fibers, so these are frequently used in combination with synthetic polymers. ${ }^{10-15}$ Furthermore, it has been found that among the cellulose esters, CTA has the highest thermal stability. ${ }^{16}$ It is known to have better hydrolytic stability and greater resistance to reactions with free chlorine and biodegradation. Therefore, CTA is used in a wide range of applications for the reason, including hemodialysis, reverse osmosis membranes, and liquid crystal displays. ${ }^{17}$

Carbon nanotubes (CNTs) possessing unique structure and properties are attractive building blocks for novel materials and devices of important practical interest. ${ }^{18}$ However, the insolu- bility or poor dispersibility of pristine CNTs in common solvents poses a serious obstacle to their further development. Various attempts have been made to obtain homogeneous CNT dispersions in both aqueous and organic media. 19, 20-24

In this work, we have fabricated CTA-MWNTs composite films with different wt $\%$ of MWNTs. The temperature-dependent DC conductivity of the composite films were studied in the temperature range $308-503 \mathrm{~K}$ at different polarizing fields, which indicates a semi-conducting behavior with the increase of temperature and increase of conductivity with the enhancement of the contents of MWNTs.

\section{Experimental Details}

All the raw materials used in the experiments were analytical reagents obtained from Sigma-Aldrich and did not receive further purification processing. The films of polymer composites of CTA and MWNTs were prepared in the laboratory by weight percent method. About $1 \mathrm{~g}$ of CTA was initially taken in a beaker along with $10 \mathrm{~mL}$ of $\mathrm{CHCl}_{3}$ and stirred for about $1 \mathrm{~h}$ to dissolve CTA completely in $\mathrm{CHCl}_{3}$. With continues stirring $10 \%$ of MWNTs was added into the $\mathrm{CHCl}_{3}$ solution containing CTA and continued stirring for $1 \mathrm{~h}$. After then the solution was transferred on a cleaned optically plane glass plate and the solution was allowed to evaporate at room temperature. Then after complete evaporation, the film was detached from glass surface. In this way the films were prepared by solution evaporation technique. Same procedure was adopted for 20, 30 and 40 weight percent MWNTs. These films were subjected to $12 \mathrm{~h}$ heating at a constant temperature of $80^{\circ} \mathrm{C}$ and for another $12 \mathrm{~h}$ at room temperature to remove the traces of solvent. The CTA film was prepared under the same conditions for comparison purposes with the composite film.

The different weight percentage of MWNTs was 10, 20, 30 and $40 \%$ in CTA to obtain CTA-MWNT composite film and in the following section the composite films are abbreviated as CMT-10, CMT-20, CMT-30, and CMT-40 respectively. For measuring the thickness, micrometer screw gauge with a least count of $0.01 \mathrm{~mm}$ was used. A small section of the sample was 
taken and mounted vertically to get clear sectional view. The thickness of the film was about $1.0 \mathrm{~mm}$.

Electrode coating and electret preparation. The parallel surfaces of the films were coated with gold by means of vacuum evaporation, and silver electrodes were placed on both surfaces with the help of silver paste to obtain better contact which acts as electrodes. The sample holder forming metal-polymer-metal system was placed in a furnace and heated up to the poling temperature of $350 \mathrm{~K}$. The sample was allowed to remain at that temperature for about $30 \mathrm{~min}$. Then electric field of desired strength was applied for $1 \mathrm{~h}$ at poling temperature with the applied electric field. The sample was allowed to cool down at room temperature, $298 \mathrm{~K}$ in the presence of applied field. Total time of polarization was adjusted to be $2 \mathrm{~h}$ in each case. On attaining room temperature, the samples were kept shorted for 30 min to eliminate the stray charges. The electrets were prepared at approximately different DC polarizing fields: $E=0.25$ $\mathrm{kV} / \mathrm{cm}, 0.5 \mathrm{kV} / \mathrm{cm}, 1.0 \mathrm{kV} / \mathrm{cm}$, and $1.5 \mathrm{kV} / \mathrm{cm}$, respectively.

Measurement of electrical conductivity. The DC electric measurements of the obtained composite films were performed within the temperature range of 308 - $503 \mathrm{~K}$ using the four-probe technique using a Keithly 224 constant current source and a Keithly 617 digital electrometer. The temperature was recorded by a digital thermometer having an accuracy of $\pm 1{ }^{\circ} \mathrm{C}$. A digital multimeter (systronics, 435 ) having an accuracy of $\pm 1 \mathrm{mV}$ was used for the measurement of voltage drop across high resistance.

\section{Results and Discussion}

Electrical properties of CTA and CMT composite films. Temperature dependent conductivity for CTA and CMT composite films was investigated within the temperature range of 308 - $503 \mathrm{~K}$ which as shown in Figure 1, and Figure 2 is conductivity with inverse temperature. The figures show that conductivity increases with an increase in temperature for all compositions, and it likewise increases with an increase in the wt $\%$ of MWNTs in CTA. The increase in conductivity with the increase in temperature indicates the semi-conducting behavior of the composites. The results of conductivity in the composite films suggest that MWNTs possesses a positive influence on the conducting property of the composites, which is triggered by the mobility of CTA counter ions at a higher temperature. Figures 3, 4, and 5 represents logarithm of the conductivity versus inverse temperature plot for the films of CTA, CMT-10, and CMT-40 thermoelectrets at different polarizing fields of $0.25 \mathrm{kV} / \mathrm{cm}, 0.5 \mathrm{kV} / \mathrm{cm}, 1.0 \mathrm{kV} / \mathrm{cm}$, and $1.5 \mathrm{kV} / \mathrm{cm}$, respectively. The conductivity versus the inverse temperature for CTA as indicated in Figure 3 shows a decreasing trend with polarizing field. This may be due to the polymeric structure of CTA. Whereas the similar plots for CMT-10 and CMT-40 as shown in Figure 4 and Figure 5 show an increasing trend by polarizing field. The increasing in conductivity in the composite films is attributed to MWNTs which has been incorporated during the mixing process. At the present state we do not have an exact information regarding the interaction between CTA and MWNTs. The study is under progressing to understand the type of interaction which responsible for the enhancement of conducting behavior as well as the activation energy in these com- posite films. The conductivity data obtained in this study are similar to those of our earlier reports. ${ }^{25-29}$

Our experimental study revealed that electrical conductivity increases with the increase in temperature. The reason for the increase in the conductivity is attributed to the thermal energy

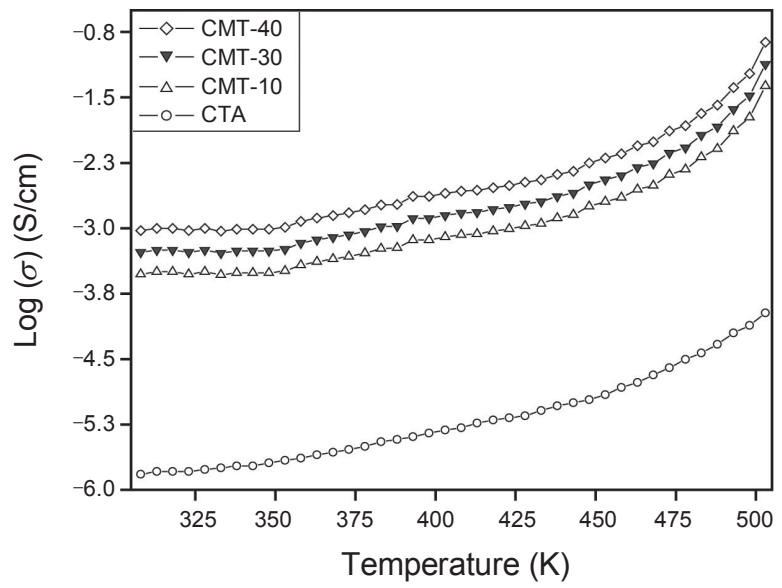

Figure 1. Temperature dependent conductivity for CTA and the composites CMT-10, CMT-30 and CMT-40.

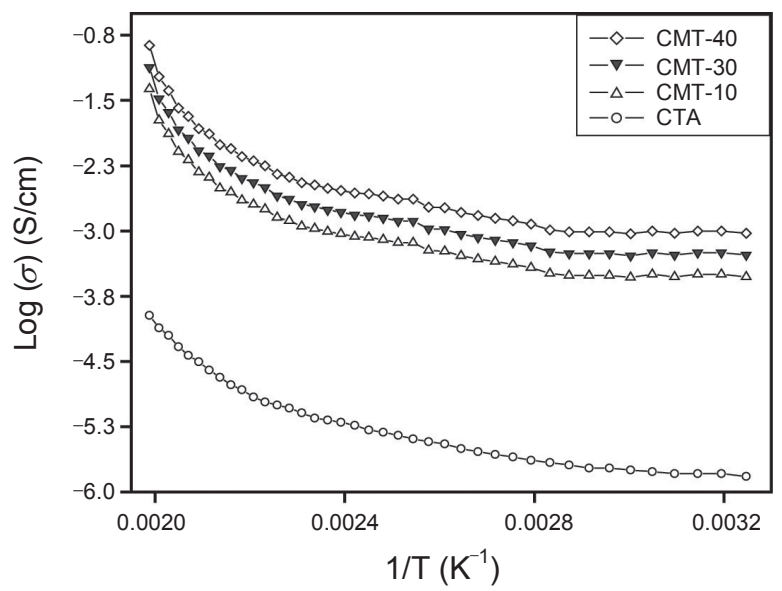

Figure 2. Conductivity versus inverses temperature for CTA and the composites CMT-10, CMT-30 and CMT-40.

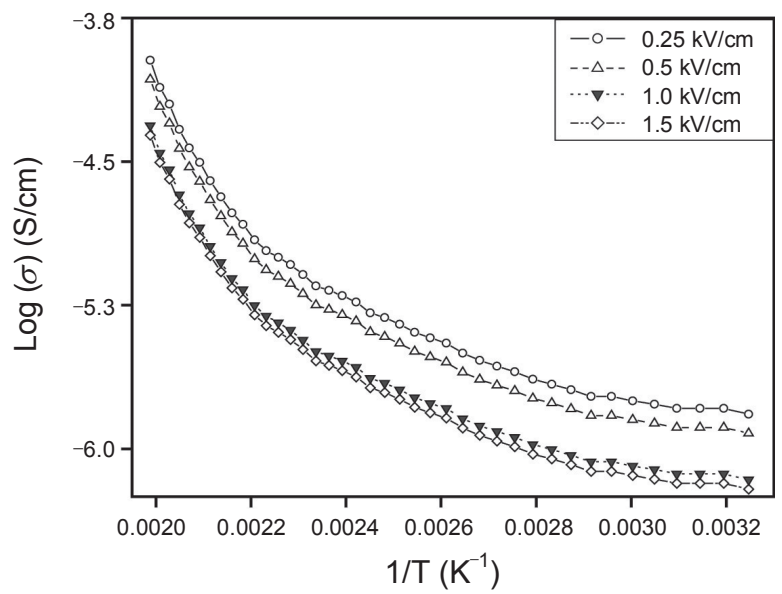

Figure 3. $\log (\sigma)$ versus inverse temperature for CTA at different polarizing fields. 
Table 1. Conductivity at different temperature and activation energy at different polarizing field for the films of CTA, CMT-10, and CMT-40

\begin{tabular}{|c|c|c|c|c|c|c|c|}
\hline \multirow{2}{*}{$\begin{array}{l}\text { Polymer/ } \\
\text { Composite }\end{array}$} & \multicolumn{3}{|c|}{ Conductivity $(\mathrm{S} / \mathrm{cm})$ at different temperature $(\mathrm{K})$} & \multicolumn{4}{|c|}{ Activation energy $(\mathrm{kcal})$ at different polarizing field $(\mathrm{kV} / \mathrm{cm})$} \\
\hline & 308 & 408 & 503 & 0.25 & 0.50 & 1.0 & 1.5 \\
\hline CTA & $1.5 \times 10^{-6}$ & $8.4 \times 10^{-4}$ & $1.1 \times 10^{-4}$ & 3.75 & 3.72 & 3.66 & 3.64 \\
\hline CMT-10 & $2.97 \times 10^{-4}$ & $1.5 \times 10^{-3}$ & $4.28 \times 10^{-2}$ & 6.60 & 8.00 & 11.55 & 17.14 \\
\hline CMT-40 & $9.41 \times 10^{-4}$ & $2.6 \times 10^{-3}$ & 0.13 & 8.92 & 11.56 & 19.26 & 21.34 \\
\hline
\end{tabular}

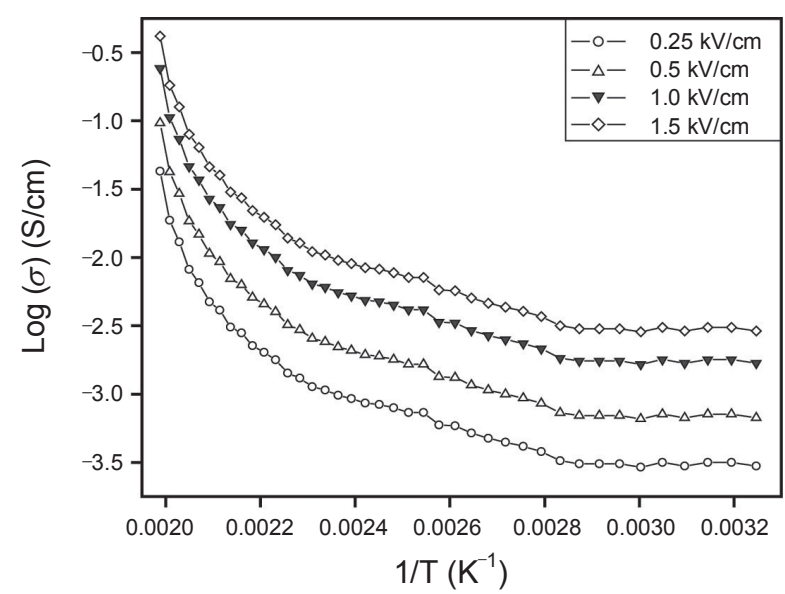

Figure 4. $\log (\sigma)$ versus inverse temperature for CMT-10 at different polarizing fields.

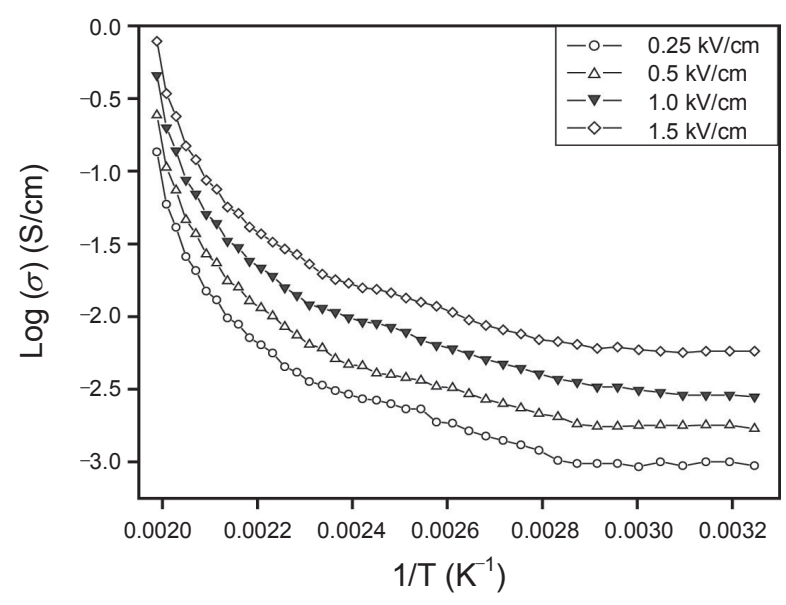

Figure 5. $\log (\sigma)$ versus inverse temperature for CMT-40 at different polarizing fields.

at higher temperature to excite electrons to the conduction band (thermal process). Such behavior can be expressed by the following Arrhenius equation:

$$
\sigma=\sigma_{\mathrm{o}} \exp \left(-E_{\mathrm{a}} / K T\right)
$$

where $\sigma$ is the conductivity, $\sigma_{\mathrm{o}}$ is the pre-exponential factor, $E_{\mathrm{a}}$ is the activation energy of conduction and $K$ the Boltzmann's constant. In Table 1, the conductivity at different temperature and activation energy using the equation at the polarizing fields for the films CTA, CMT-10 and CMT-40 are given. By the Table 1, both the conductivity and the activation energy for CTA are smaller as compared to the composite films and remain more or less same even after increasing the temperature. The conductivity and the activation energy for the composites CMT-10 and CMT-40 have increased in a larger quantity as compared to CTA with temperature.

MWNTs possess a highly conductive graphite structure which is highly responsible for the increase in the conductivity for the above composites. ${ }^{30}$ Their highly conductive graphitic structure should be efficient enough to establish an effective conducting network inside the matrix of these polymers. It appears the alignment of MWNTs in the composites films is more established as the temperature is increased, therefore an increase in the activation energy and so as the conductivity. This behavior is likely resulted from the three-dimensional network of nanotubes present in the composite films. ${ }^{31,24}$

\section{Conclusion}

The fabricated CTA-MWNTs composite films with different wt $\%$ of MWNTs were fabricated and studied for the temperature-dependent DC conductivity in the temperature range $308-503 \mathrm{~K}$ at different polarizing fields. The composite films indicate a semi-conducting behavior with an increase in the activation energy and conductivity. It may be concluded that the enhancement in conducting behavior of these composite films is due to the presence of MWNTs. More detailed work is under progress to understand the interaction of CTA and CNT in the composites responsible for the improved conductivity. The composites may find applications such as anti-static materials, in electrostatic painting, or as protective coatings for electronic components.

Acknowledgments. This research was supported by Basic Science Research Program through the National Research Foundation of Korea (NRF) funded by the Ministry of Education, Science and Technology (00042009026-00).

\section{References}

1. Friend, R. H.; Gymer, R. W.; Holmes, A. B.; Burroughes, J. H.; Marks, R. N.; Taliani, C. D. D. C.; Bradley, D.; Dos Santos, A.; Brédas, J. L.; Lögdlund, M.; Salaneck, M. R. Nature 1999, 397, 121.

2. Lappas, A.; Zorko, A.; Wortham, E.; Das, R. N.; Giannelis, E. P.; Cevc, P.; Arcon, D. Chem. Mater. 2005, 17, 1199.

3. Howard, W. E. Sci. Am. 2004, 290, 76.

4. Sirringhuas, H.; Tessler, N.; Friend, R. H. Science 1998, $280,1741$.

5. Dimitrakopoulos, C. D.; Mascaro, D. J. IBMJ. Res. Dev. 2001, 45, 11.

6. Yu, G.; Gao, J.; Hummelen, J. C.; Wud, F.; Heeger, A. J. Science 1995, 270, 1789. 
7. Brabec, C. J.; Sariciftci, N. S.; Hummelen, J. C. Adv. Funct. Mater. 2001, 11, 15.

8. Huang, M. R.; Li, X. G. Gas Sep. Purif. 1995, 9, 87.

9. Li, X. G.; Huang, M. R.; Lin, G.; Yang, P. C. J. Appl. Polym. Sci. 1994, 51,743 .

10. De Smet, R.; Dhondt, A.; Eloot, S.; Galli, F.; Watrloos, M. A.; Vanholder, R. Nephrol. Dial. Transplant. 2007, 22, 2006.

11. Tsai, Y. L.; Tien, H. T.; Chen, H. J. Microencapsulation 2000, 17, 413.

12. Wolter, A.; Ewa, B.; Genoud, F.; Pron, A.; Nechtschein, M. Synth. Met. 1997, 84, 753 .

13. Pron, A.; Zagorska, M.; Nicolau, Y.; Genoud, F.; Nechtschein, N. Synth. Met. 2004, 64, 748.

14. Platt, A. E.; Wallace, T. C. Encyclopedia of Chemical Technology; Grayson, M., Ed.; John Wiley: New York, 1983; p 21.

15. Lesaffer, G.; Smet, R. D.; Lameire, N.; Dhondt, A.; Duym, P.; Vanholder, R. Nephrol Dial Transplant 2000, 15, 50.

16. Noorjahan, S. E.; Sekar, S.; Sastry, T. P. Curr. Sci. 2008, 90(7), 958.

17. Kastelan, K. L.; Dananic, V.; Kunst, B.; Kosutic, K. J. Membr. Sci. 1996, 109, 223.

18. Iijima, S. Nature 1991, 354, 56.

19. Hong, C. Y.; You, Y. Z.; Pant, C. Y. Chem. Mater. 2005, 17, 2247.

20. Sinani, V. A.; Gheith, M. K.; Yaroslavov, A. A.; Rakhnyanskaya, A. A.; Sun, K.; Mamedov, A. A.; Wicksted, J. P.; Kotov, N. A. J. Am. Chem. Soc. 2005, 127, 3463.
21. Huang, W. J.; Lin, Y.; Taylor, S.; Gaillard, J.; Rao, A. M.; Sun, Y. P. Nano Lett. 2002, 2, 231.

22. Moore, V. C.; Strano, M. S.; Haroz, E. H.; Hauge, R. H.; Smalley, R. E.; Schmidt, J.; Talmon, Y. Nano Lett. 2003, 3, 1379.

23. Shvartzman-Cohen, R.; Nativ-Roth, E.; Baskaran, E.; Levi-Kalisman, Y.; Szleifer, I.; Yerushalmi-Rozen, R. J. Am. Chem. Soc. 2004, 126, 14850.

24. Zhang, H.; Li, H. X.; Cheng, H. M. J. Phys. Chem. B 2006, 110, 9095.

25. Basavaraja, C.; Pierson, R.; Vishnuvardha, T. K.; Huh, D. S. Euro. Polym. J. 2008, 44, 1556.

26. Basavaraja, C.; Veeranagouda, Y.; Lee, K.; Pierson, R.; Revanasiddappa, M.; Huh, D. S. Bull. Korean Chem. Soc. 2008, 29(12), 2423.

27. Basavaraja, C.; Pierson, R.; Huh, D. S.; Venkataraman, A.; Basavaraja, S. Macromol. Res. 2009, 17(8), 609.

28. Pierson, R.; Basavarja, C.; Kim, N. R.; Jo, E. A.; Huh, D. S. Bull. Korean Chem. Soc. 2009, 30(9), 2057.

29. Basavarja, C.; Kim, N. R.; Jo, E. A.; Pierson, R.; Huh, D. S.; Venkatarman, A. Bull. Korean Chem. Soc. 2009, 30(11), 2701.

30. Safadi, B.; Andrews, R.; Grulke, E. A. J. Appl. Polym. Sci. 2002, $84,2660$.

31. Zengin, H.; Zhou, W. S.; Jin, J. Y.; Czerw, R.; Smith, D. W.; Echegoyen, L.; Carroll, D. L.; Foulger, S. H.; Ballato, J. Adv. Mater. 2002, 14, 1480. 